Cita: Garriga, Cecilio y Francesc Rodríguez (2006): "La 15ª edición del DRAE (1925): voces técnicas y dialectales", en Mar Campos Souto e Ignacio Pérez Pascual, eds., El diccionario de la Real Academia Española: ayer y hoy, A Coruña, Universidade da Coruña, Anexos de Revista de Lexicografía, 1, pp. 99-116. https://doi.org/10.17979/spudc.9788497497466.099

\title{
La 15ª edición del DRAE (1925): voces técnicas y dialectales*
}

\author{
CECILIO GARRIGA \\ FRANCESC RODRÍGUEZ \\ Grupo NEOLCYT \\ Universitat Autònoma de Barcelona
}

\section{INTRODUCCIÓN}

Existe un consenso generalizado acerca de que la edición académica de 1925 es una de las más importantes en el devenir del diccionario. ${ }^{1}$ La mayoría de los bosquejos históricos sobre la lexicografía del español se fijan, sobre todo, en el cambio de nombre que experimenta el repertorio académico a partir de esta edición, ya que el título tradicional de Diccionario de la lengua castellana que se había acuñado en el Diccionario de Autoridades (Real Academia Española 1726-1739) se abandona, y se toma el de Diccionario de la lengua española. ${ }^{2}$

Sin embargo, con ser importante, este aspecto no es el único destacable en la $15^{\mathrm{a}}$ edición. Por un lado, la Academia ya había tomado partido por la inclusión de dialectalismos y voces propias de América, especialmente a partir de la $12^{\text {a }}$ edición; ${ }^{3}$ por otro, el diccionario apunta desde su «Advertencia» inicial otros dos aspectos que pueden ser fundamentales en su análisis: la inclusión de muchas voces técnicas y una mayor «condescendencia con el uso».

* Este estudio se inserta en el marco del proyecto de investigación «Diccionario histórico del español moderno de la ciencia y de la técnica», financiado por el Ministerio de Educación y Ciencia (HUM2004-00486).

1 Alvar la califica de memorable e importantísima (1992: 16 y 18).

2 Así Seco (1988: 92), Alvar Ezquerra (1993: 228), Abad (1997: 103), etc.

3 Ya en las Reglas de 1869 al hablar de los Americanismos, se dice: «Se incluirán, con indicación de su procedencia, las voces y locuciones americanas cuya utilidad esté reconocida, cuidando mucho de que la inclusión no se extienda á vocablos y giros caprichosos ó antigramaticales» (1869: 2). Estas recomendaciones se mantienen sin cambios en las Reglas de 1872. 
Otro aspecto que no se puede perder de vista es la ubicación del diccionario entre las ediciones académicas. Para no remontarse demasiado en el tiempo, hay que remitir, como mínimo, a la $12^{\mathrm{a}}$ edición ( $\left.D R A E-1884\right)$, en la que se producen cambios profundos tanto en la macroestructura como en la microestructura del diccionario. Las Reglas de 1869 y de 1872 que la Academia elabora para la revisión de esta edición siguen teniendo gran influencia en las ediciones posteriores, hasta el punto de no haberse elaborado ningunas otras. Los ecos de los comentarios a la edición de 1884, unos más filológicos, otros más airados, ${ }^{4}$ traspasan también la frontera del siglo, y se proyectan en las primeras ediciones del xx. Así, las ediciones $13^{\mathrm{a}}(D R A E-1899)$ y $14^{\mathrm{a}}$ (DRAE-1914) sirven de tránsito a la edición objeto de este estudio, sin aportar demasiadas innovaciones. Y no debe olvidarse una secuela del trabajo de la Corporación para la edición de 1925, como es la primera edición del Diccionario manual e ilustrado de la lengua española, publicado en 1927 bajo presupuestos teóricos distintos a los del diccionario normativo. ${ }^{5}$

También es importante reparar en algunos de los académicos que en ese momento forman parte de la Corporación, ya que su presencia puede justificar los profundos cambios que se producen en la edición. Así, entre la nómina de académicos que aparece en las primeras páginas figuran nombres de filólogos tan importantes como los de Menéndez Pidal, ${ }^{6}$ Alemany y Bolufer ${ }^{7}$ o Julio Casares, ${ }^{8}$ además de científicos como Torres Quevedo, ${ }^{9}$ Daniel de Cortázar, ${ }^{10}$ Rodríguez Carracido o Ramón y Cajal.

${ }^{4}$ En el ámbito de las voces americanas es muy completa la descripción de Clavería (2004: 625) sobre las críticas externas a la $12^{\mathrm{a}}$ edición del diccionario: Antonio de Valbuena, Rodríguez Marín, Álvarez Sereix, Rodríguez y Martín, M. Pardo de Figueroa, R. Palma, Viada, Rivodó, Zerolo, etc., así como las respuestas de los académicos. En el mismo trabajo se apunta como aspecto más relevante de la edición de 1899 la inclusión de términos de la Botánica y la Zoología, dentro del objetivo general que persigue la mejora de las definiciones lexicográficas (2004: 628).

5 Véase, a este respecto, el plan que Menéndez Pidal presentó en 1922 para la elaboración del Diccionario manual (Seco 1994 y Abad 1997: 105). Una visión más detallada en Seco (1993), y una breve noticia sobre su evolución en Zamora Vicente (1999: 374).

${ }^{6}$ Sobre Menéndez Pidal, véase Pérez Pascual (1998).

7 Según Zamora Vicente (1999: 206), Alemany fue el encargado de la edición del Diccionario manual de la Academia (DRAE-1927) y autor de un Diccionario de la lengua española (1917).

8 Cabe señalar que Casares lee su discurso de ingreso el 8 de mayo de 1921, con el título de «Nuevo concepto del Diccionario de la lengua» (Zamora Vicente 1999: 162), publicado algo más tarde junto a algunos otros ensayos (Casares 1941).

9 El discurso de ingreso de Torres Quevedo «Acerca del proyecto de Unión Internacional Hispanoamericana de Bibliografía y Tecnología Científicas» (1920) está en la base de los vocabularios científicos de la Academia (Zamora Vicente 1999: 182).

${ }_{10}$ Importante colaborador en las tareas lexicográficas, y muy concienciado por castellanizar tecnicismos extranjeros (Zamora Vicente 1999: 255). 
Los estudios metalexicográficos sobre los diccionarios de la Academia que toman como punto de partida los prólogos de las ediciones tienen razones para destacar la $15^{\mathrm{a}}$ como una de las más importantes. En efecto, la misma Academia empieza diciendo que «esta edición décima quinta del diccionario difiere de la décima cuarta probablemente más que cualquiera de las otras difiere de su inmediata anterior» (1925. VII). Esta afirmación se sostiene, entre otras, en las siguientes razones:

- Incorporación de «gran número de acepciones y voces nuevas que por olvido u otras causas no se habían incorporado en las ediciones anteriores». Este aspecto se cubre en dos vertientes: voces técnicas, «en especial las que tienen alguna difusión fuera del círculo de los profesionales», para poner el diccionario «al nivel del estado actual de las ciencias y de las artes»; el uso, ya que esta edición se propone «incorporar al Diccionario la mayor parte del habla común de las personas ilustradas». Admite que la Corporación «retrasó, a veces con extremada prudencia, la sanción debida al neologismo aceptable».

- Atención a los regionalismos de España y de América. Se valoran los «provincialismos» de ambos lados del Atlántico, porque además pueden coincidir parcialmente. Se recogen, sobre todo, voces que se refieren a animales, plantas, costumbres, peculiares de América. Solicita la colaboración de las academias correspondientes, y justifica el cambio del adjetivo castellana por española «como consecuencia de esta mayor atención consagrada a las múltiples regiones lingüísticas, aragonesa, leonesa e hispanoamericana».

Aunque en estos dos aspectos no se agota la complejidad de esta $15^{\text {a }}$ edición, son lo suficientemente significativos como para centrar nuestra atención en este estudio parcial. Así, nos proponemos comprobar los juicios realizados por otros investigadores a partir de las afirmaciones de la propia Academia en la «Advertencia», aprovechando los estudios transversales existentes sobre la lengua técnica en los diccionarios académicos y sobre la presencia de dialectalismos. Estos datos serán cotejados con los resultados de un recuento realizado para este trabajo, lo que permitirá comprobar el alcance de las novedades introducidas por la Academia en esta edición. Teniendo en cuenta todos estos factores, se prestará una especial atención a la nomenclatura para ver los cambios realizados respecto a la $14^{\mathrm{a}}$ edición. Además, comprobaremos la pervivencia en ediciones posteriores de algunas novedades introducidas en 1925. 


\section{VOCES TÉCNICAS}

La Academia se refería en la «Advertencia» a este aspecto como uno de los más destacados de la edición, al anunciar un gran número de «acepciones y voces nuevas». En efecto, se trata de una de las cuestiones más controvertidas de la lexicografía española moderna, como se ha destacado en trabajos de diversos autores. ${ }^{11}$

Hay que recordar, en este sentido, que en las Reglas de 1869 se determina que «se incluirán las voces de los lenguajes técnicos que hayan pasado al vulgar o al culto, y puedan, a juicio de la Academia, formar parte del fondo de la lengua» (1869: 2); y que Cuervo (1874: 120) animaba a la Academia a intervenir para dirigir el uso de la lengua, en especial para evitar el afincamiento de voces técnicas mal adaptadas (Seco 1987: 180). También estuvo presente la discusión en el Congreso Literario HispanoAmericano de 1892, con repercusiones importantes en la edición de $1899 .{ }^{12}$

El primer aspecto que cabe destacar es el de la aparición de diecisiete nuevas abreviaturas referidas a especialidades científicas o técnicas, no presentes en la $14^{\mathrm{a}}$ edición (DRAE-1914), lo que supone más del 30\% de las nuevas abreviaturas de 1925 .

\begin{tabular}{||l|l||}
\hline Anat. & Anatomía \\
\hline Antrop. & Antroplogía \\
\hline Cerraj. & Cerrajería \\
\hline Electr. & Electricidad \\
\hline Etnogr. & Etnografia \\
\hline Etnol. & Etnología \\
\hline Ferr. & Ferrocarriles \\
\hline Filol. & Filología \\
\hline Fren. & Frenología \\
\hline Grab. & Grabado \\
\hline Indum. & Indumentaria \\
\hline Lit. & Literatura \\
\hline
\end{tabular}

11 Tanto Alvar López (1992: 10 y ss.) como Alvar Ezquerra (1993a: 229-230) destacan estos aspectos a partir de las referencias que la Academia hace en los prólogos de sus diccionarios. Interesantes comparaciones entre las ediciones de la primera mitad del s. XIX se realizan en Azorín (1996-1997) y en Azorín y Santamaría (1998). Son numerosos los estudios sobre las voces técnicas en diversos diccionarios. Y de un tiempo a esta parte vamos disponiendo de trabajos de investigación que acotan diversas partes del léxico técnico y estudian su implantación en los diccionarios. Así, Rodríguez Ortiz (1994 y 1997) para el léxico del ferrocarril, Moreno Villanueva (1995) para el de la electricidad, Garriga (1996) para el de la economía, Garriga (1996-1997) para el de la química, Gállego (1999) para el de la fotografía, Bajo (1999) para la enología, etc.

12 Gutiérrez Cuadrado y Pascual (1992) realizan una pormenorizada descripción de las discusiones lingüísticas del Congreso. 


\begin{tabular}{||l|l|}
\hline Liturg. & Liturgia \\
\hline Ópt. & Óptica \\
\hline Paleont. & Paleontología \\
\hline Pat. & Patología \\
\hline Reloj. & Relojería \\
\hline
\end{tabular}

De ellas, como señala Battaner (1996: 100), anatomía, cerrajería, literatura y óptica ya habían estado anteriormente en el diccionario. ${ }^{13}$ En cualquier caso, a partir de estos datos, esta edición se convierte en la tercera más importante en la historia de los diccionarios académicos en cuanto a la introducción de nuevas abreviaturas, después de la $12^{\mathrm{a}}$ (DRAE-1884), en la que se replantea a fondo el problema de las marcas técnicas (Garriga 2001: 270), y la $19^{\text {a }}$ (DRAE-1970) que numéricamente rebasa a las anteriores.

Pero además, hay otra abreviatura que resulta muy significativa y que se incorpora precisamente en esta edición: Tecn. 'Tecnicismo'. ${ }^{14}$ Este hecho muestra la preocupación creciente de la Academia por señalar este tipo de voces. ${ }^{15}$

Entre los 217 nuevos lemas que, bajo la letra $\mathrm{F},{ }^{16}$ se incorporan a la $15^{\mathrm{a}} \mathrm{ed}$. (DRAE-1925) aparecen 15 acepciones con marcación referida a los siguientes campos: gramática (3), albañilería y arquitectura (2), y carpintería, fotografía -Fotogr. en abreviaturas y Fot. en el cuerpo-, pintura, medicina, zoología, botánica, física y blasón (1). Ninguna de ellas corresponde a las nuevas marcas científico-técnicas recogidas en las «Abreviaturas» de esta edición, lo que confirma la tendencia a que la incorporación de las marcas se anticipe a la inclusión de los términos marcados del campo al que se refieren. ${ }^{17}$

13 Según Battaner (1996: 100), todas ellas habían desaparecido en la 12a ed. (DRAE-1884).

14 Posteriormente, en la $19^{\mathrm{a}}$ edición de 1970, el DRAE distingue las marcas de tecn. 'tecnicismo' y Tecnol. 'Tecnología'; en la 22 ed. (DRAE-2001) ya únicamente aparece la marca Tecnol. 'tecnologías'.

15 Es oportuno recordar de nuevo a Cuervo (1874: 120-121), quien opinaba que «El Diccionario debe consignar y distinguir las acepciones clásicas y populares de las científicas». Argumentaba que las ciencias tienen sus diccionarios facultativos, mientras que los «autores clásicos y el pueblo» no tienen otro diccionario que éste. «Por tanto las Academias que trabajan en éste, deben ser infatigables en enriquecerlo y mejorarlo sin reserva en lo clásico y popular, bastando en lo científico que lo nivelen a los adelantamientos y progresos modernos, sin necesidad de profundizarlos, por medio de breves definiciones marcadas con la abreviatura correspondiente a la respectiva facultad».

16 El recuento exacto de lemas en la $15^{\text {a }}$ edición (DRAE-1925) arroja la cifra de 67389 entradas, frente a las 60188 de la $14^{\mathrm{a}}$ edición (DRAE-1914). Este aumento de 7201 entradas supone un incremento de un $11.96 \%$ sobre la edición anterior. La letra $\mathrm{F}$ es una de las más representativas a juzgar por el número de incorporaciones respecto a la edición anterior, con un aumento del $10.26 \%$, de 2031 a 2236 .

17 En otros casos, pero en la misma línea, hallamos nuevas acepciones marcadas en términos ya existentes: Arq. faja 5, faja 6, fajón 2; Com. falencia 2; For. falsificación 2, fatal 4, mala fe 2; Impr. fe de erratas; Mar. farol de situación; Pint. y Esc. factura 5; o Taurom. farol 5. 
También resultan de gran interés para nosotros los estudios realizados sobre el léxico de diversos campos de la ciencia y de la técnica que se han realizado en los últimos años, en especial sobre la electricidad, el ferrocarril, la fotografía y la enología.

A través del estudio de Moreno Villanueva (1995) en relación con léxico de la electricidad, sabemos que la $15^{\mathrm{a}}$ edición recoge por vez primera la marca Electr. y documenta 94 nuevas acepciones de las 835 presentes en 1992 referidas a la electricidad. Hasta 1970 se erige, por tanto, en la edición con mayor número de incorporaciones de este campo y, concretamente, de su aplicación a la radioelectricidad y a la telegrafía, entre las que se cuentan voces como cortocircuito, electrocutar y electrocución, fusible o hidroeléctrico. ${ }^{18}$

Aunque la marca de Ferr. 'ferrocarril' también aparece por primera vez en esta edición, por los estudios de Rodríguez Ortiz (1994 y 1997) sabemos que las voces del campo del ferrocarril empiezan a registrarse ya en la $10^{\mathrm{a}}$ ed. (DRAE-1852). Sin embargo, tras un aumento progresivo en las ediciones siguientes, la $15^{\mathrm{a}}$ ed. de 1925 , con 43 incorporaciones, es de nuevo la que las registra en mayor número. Se incluyen por primera vez voces como abanico, cambiavía, carbonera, detasa, electrificación, encarriladera, tractocarril, tren botijo o vía muerta.

El ámbito de la fotografía también resulta significativo. Aunque la marca aparece por primera vez en la $13^{\mathrm{a}}$ ed. (DRAE-1899), ya se habían registrado numerosas incorporaciones en la $12^{\mathrm{a}}$ (DRAE-1884). En cualquier caso, como se demuestra en el estudio de Gállego Paz (1999), la $15^{\text {a }}$ edición, con 34 incorporaciones, solo se ve superada por la $20^{\mathrm{a}}(D R A E-1984)$ y la $21^{\mathrm{a}}$ ed. (DRAE-1992). Se registran en esta edición voces, en su mayor parte relacionadas con la elaboración, como calitipia, catatipia, cinematografia, fotograbar, fototipia, platinotipia, telemetría, etc. También resulta relevante el dato referido a la revisión de las definiciones. De las 91 acepciones introducidas hasta 1925 en relación con la fotografía, 25 de ellas, un $27.5 \%$, experimentan algún tipo de variación.

En cuanto al vocabulario enológico, de nuevo es la edición de 1925 la que incorpora un mayor número de acepciones en este campo: un total de 67 de las 825 que hallamos en 1992, en su mayor parte referidas a derivados del vino. Asimismo, como señala Bajo (1999), de los términos relativos al vino que tienen una marca diatópica peninsular en 1992, el 30\% se incorporan en 1925. En esta misma edición y por primera vez, además, se incorporan a este campo marcas diatópicas no peninsulares. A ello se une la incorporación de acepciones con otras marcas (fig., fam., ant., desus., Arqueol.). Los datos comentados se presentan en la siguiente tabla:

18 Es interesante seguir el debate sobre las unidades eléctricas, introducidas en el suplemento de la $13^{\mathrm{a}}$ edición (DRAE-1899) en su adaptación al español, y en el suplemento a la $14^{\mathrm{a}}$ ed. (DRAE-1914) siguiendo la nomenclatura internacional. Hay referencias a ello en Moreno Villanueva (1998). 


\begin{tabular}{|l|c|c|c|c|c||c||c|c|c|c|c|c|}
\hline \hline DRAE & $\begin{array}{c}\text { Hasta } \\
1852\end{array}$ & 1869 & 1884 & 1899 & 1914 & 1925 & 1936 & 1947 & 1956 & 1970 & 1984 & 1992 \\
\hline Electricidad & 38 & 14 & 42 & 67 & 37 & 94 & 53 & 32 & 58 & 152 & 123 & 140 \\
\hline Ferrocarril & 3 & 33 & 32 & 25 & 14 & 43 & 13 & 2 & 5 & 16 & 18 & 16 \\
\hline Fotografía & 16 & 14 & 25 & 25 & 10 & 34 & 26 & 7 & 14 & 32 & 38 & 65 \\
\hline Enología & 464 & 17 & 60 & 27 & 25 & 67 & 53 & 9 & 14 & 23 & 36 & 39 \\
\hline
\end{tabular}

Pero estos datos no dan la medida exacta de las voces técnicas o científicas incorporadas. Como se ha venido repitiendo, el número de voces técnicas presentes en el Diccionario sin marca es muy numeroso. Así, en la muestra utilizada para este estudio, se encuentran voces científicas o técnicas marcadas junto a otras que no lo están, y cuya especialización está fuera de discusión, como se muestra en los siguientes ejemplos:

\begin{tabular}{|c|c|}
\hline Incorporaciones con marca & Incorporaciones sin marca \\
\hline $\begin{array}{l}\text { FISIOTERAPIA. (Del gr. } \varphi \text { } \sigma ı \varsigma \text {, naturaleza, } \\
\text { y } \theta \in \rho \alpha \pi \in i ́ \alpha \text {, curación.). f. Med. Método cura- } \\
\text { tivo por medio de los agentes naturales: aire, } \\
\text { agua, luz, etc. } \\
\text { FISIRROSTRO, TRA. (Del lat. fissus, hen- } \\
\text { dedura, y rostrum, pico.) adj. Zool. Dícese del } \\
\text { pájaro que tiene el pico corto, ancho, aplasta- } \\
\text { do y profundamente hendido.\| 2. m. pl. Zool. } \\
\text { Familia de estos pájaros. }\end{array}$ & 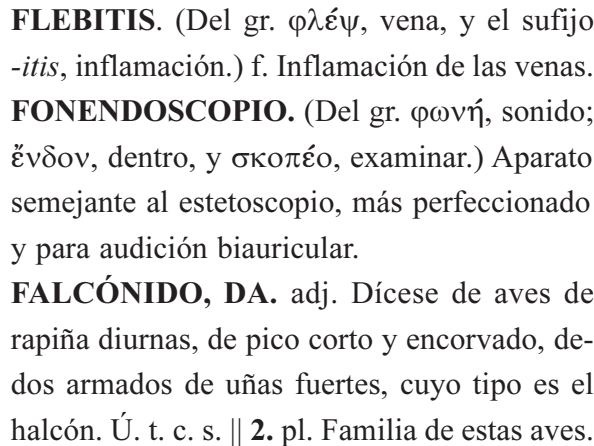 \\
\hline
\end{tabular}

Así, en la muestra utilizada, además de fisioterapia y fisirrostro, se incorporan las entradas de fijador, flexional, foliolo, fonema, forjado, formalete, fotófono, francocuartel, fratás y fricativo. Cabe destacar el caso de fijador, entrada que incorpora hasta cinco acepciones, cuatro de ellas con marca de especialidad:

FIJADOR, RA. adj. Que fija. || 2. Albañ. Operario que se emplea en introducir el mortero entre las piedras y en retundir las juntas. || 3. Carp. El operario que fija las puertas y ventanas en sus cercos. $\|$ 4. Fot. Líquido que sirve para fijar. || 5. Pint. Líquido que esparcido por medio de un pulverizador sirve para fijar dibujos hechos con carbón o con lápiz.

En otros casos son especialmente significativos los cambios experimentados por numerosas voces técnicas para modernizar las definiciones de acuerdo con los avances de la ciencia, como ocurre en el siguiente ejemplo: 


\begin{tabular}{|c|c|}
\hline 1914 & 1925 \\
\hline $\begin{array}{l}\text { Rayo. (Del lat. rad̆us.) m. Línea de luz que } \\
\text { procede de un cuerpo luminoso, y especialmen- } \\
\text { te las que vienen del sol. } \|{ }^{2} \text { Cada una de las } \\
\text { piezas cilíndricas o prismáticas que a modo de } \\
\text { radios de círculo unen el cubo a las pinas de } \\
\text { una rueda. } \|^{3} \text { Fuego eléctrico que se despren- } \\
\text { de repentina y violentamente de una nube. } \| \\
{[\ldots] \text {. }}\end{array}$ & $\begin{array}{l}\text { RAYO. (Del lat. radius.) m. Cada una de las } \\
\text { líneas generalmente rectas que parten del pun- } \\
\text { to en que se produce una determinada forma } \\
\text { de energía y señalan la dirección en que ésta } \\
\text { es transmitida por el movimiento vibratorio del } \\
\text { éter. Su naturaleza es siempre la misma, y sólo } \\
\text { difieren unos de otros rayos en la longitud de } \\
\text { ondas etéreas correspondientes, que varían } \\
\text { desde una cienmilésima de micra, en los ra- } \\
\text { yos X, hasta algunos kilómetros, en las ondas } \\
\text { hertzianas. } \| \mathbf{2} \text {. Línea de luz que procede de un } \\
\text { cuerpo luminoso, y especialmente las que vie- } \\
\text { nen del sol. \|3. Chispa eléctrica de gran inten- } \\
\text { sidad producida por descarga entre dos nubes } \\
\text { o entre una nube y la tierra. } \| \mathbf{4} \text {. V. Corona de } \\
\text { rayos. \| 5. Cada una de las piezas cilíndricas } \\
\text { o prismáticas que a modo de radios de círcu- } \\
\text { lo unen el cubo a las pinas de una rueda. } \| \mathbf{6} \text {. } \\
\text { [...]. }\end{array}$ \\
\hline
\end{tabular}

\section{Voces dialectales}

Como hemos comentado, este es uno de los aspectos más frecuentemente señalado al referirse a las novedades de la $15^{\mathrm{a}}$ edición. En efecto, la Academia así lo declara en la «Advertencia» y lo muestra en las abreviaturas: entre las novedades, destacan once nuevas indicaciones referidas a provincias o regiones de España y otras catorce a países o lugares americanos. Y otro dato sobradamente señalado: la sustitución del adjetivo castellana por española para denominar la lengua y dar título al diccionario.

En efecto, el diccionario considera el castellano como la 'lengua nacional de España', mientras que a español le da un significado más amplio, introducido precisamente en esta $15^{\mathrm{a}}$ edición:

\begin{tabular}{||l|l||}
\hline \multicolumn{1}{|c|}{1914} & \multicolumn{1}{|c|}{1925} \\
\hline Castellano, na. (Del lat. castellanus) $[\ldots] \|^{5}$ & CASTELLANO, NA. (Del lat. castellanus) \\
m. Idioma castellano, o sea, lengua nacional & $\begin{array}{l}\text { [...] || 6. m. Idioma castellano, o sea, lengua } \\
\text { ne España. }\end{array}$ \\
\hline
\end{tabular}


Español, la. adj. Natural de España. U. t. c. s. $\|{ }^{2}$ Perteneciente a esta nación. $\|{ }^{3}$ V. Era española. $\|{ }^{4} \mathrm{~m}$. Lengua española. $\|{ }^{5}$ A la española. m. adv. Al uso de España.
ESPAÑOL, LA. adj. Natural de España. U. t. c. s. || 2. Perteneciente a esta nación. \| 3. V. Era española. || 4. m. Lengua española, originada principalmente en Castilla, y hablada también en casi todas las repúblicas americanas, en Filipinas y en muchas comunidades judías de Oriente y del norte de África. $\|$ 5. A la española. m. adv. Al uso de España.

A juicio de Abad (1997: 103), la visión de Menéndez Pidal y de García de Diego del español como un complejo dialectal fue determinante a la hora de decidirse a incorporar el caudal léxico de las variedades internas del español. En efecto, como documenta Pérez Pascual (1998: 158), es precisamente Menéndez Pidal quien defiende ante la Academia el cambio de lengua castellana por lengua española en todas las producciones de la Academia; la propuesta, aunque con alguna resistencia, sale adelante, y así la Gramática (1922) y el diccionario (1925) pasan a llamarse de la lengua española. Esa concepción de la lengua es la que se refleja en la nueva acepción $4^{\mathrm{a}}$ de español. ${ }^{19}$

Pero el interés de la Academia por las voces dialectales venía de lejos. Alvar Ezquerra (1993b: 319) explica cómo la Corporación se preocupa desde el principio de sus trabajos por los regionalismos. Y aunque desde el $D A(D A-1726-1739)$ estas voces habían estado presentes en el diccionario (Salvador Rosa 1985), es en la 12a edición de la Academia ( $D R A E$-1884) cuando se amplía de manera significativa el número de abreviaturas que hacían referencia a los «provincialismos». Entre ellas se mezclaban las que señalaban usos peninsulares y americanos, aunque estos últimos, si los países a los que se adscribían habían obtenido la independencia, omitían la nota de provincial (Garriga 2001: 272). Este esquema de marcación se mantiene en la $13^{\mathrm{a}}$ ed. (DRAE-1899), mientras que en la $14^{\mathrm{a}}$ ed. (DRAE-1914) se pierde la nota de «prov. $d e . . . » \mathrm{y}$ se igualan todas las marcas dialectales, sean de España o América. ${ }^{20}$

Y así se llega a la $15^{\mathrm{a}}$ ed. en la que se puede establecer ya -así lo hace la Academia- una diferencia clara entre «regionalismos de España y de América», a los que también llama americanismos. En cualquier caso, la importancia de esta edición

19 Sobre el nombre de la lengua, puede verse el clásico estudio de Alonso (1940), o los posteriores de González Ollé (1978), Mondéjar (1979) o Lope Blanch (1983). Un momento importante en ese debate lingüístico de fin de siglo fue el Congreso Literario Hispano-Americano de 1892, cuyo análisis se puede seguir en Gutiérrez Cuadrado y Pascual (1992). Las relaciones existentes entre España y América en el ámbito lingüístico en Gutiérrez Cuadrado (1989).

20 Téngase en cuenta que las colonias americanas habían alcanzado todas ellas su independencia. 
en lo que a incorporación de voces dialectales se refiere está fuera de toda duda. Según el recuento realizado a partir de la muestra utilizada, alrededor del $40 \%$ de las incorporaciones a esta edición lleva alguna marca dialectal.

\section{Regionalismos}

En la tabla de abreviaturas aparecen las siguientes 38 marcas peninsulares -con asterisco las 12 de nueva incorporación-:

\begin{tabular}{|c|c|}
\hline Ál. ${ }^{*}$ & Álava \\
\hline Albac. & Albacete \\
\hline Alic. & Alicante \\
\hline Alm. & Almería \\
\hline And. & Andalucía \\
\hline$A r$ & Aragón \\
\hline Ast. & Asturias \\
\hline Áv. & Ávila \\
\hline Bad. & Badajoz \\
\hline Burg. & Burgos \\
\hline C. Real* & Ciudad Real \\
\hline Các.* & Cáceres \\
\hline Cád.* & Cádiz \\
\hline Can. & Canarias \\
\hline Cord. & Córdoba \\
\hline Cuen. & Cuenca \\
\hline Cuen.* & Cuenca \\
\hline Extr. & Extremadura \\
\hline Gal.* & Galicia \\
\hline Gran. & Granada \\
\hline Guad. o Guadal.* & Guadalajara \\
\hline Guip.* & Guipúzcoa \\
\hline $\log { }^{*}{ }^{*}$ & Logroño \\
\hline Mál. & Málaga \\
\hline Mál.* & Málaga \\
\hline Murc. & Murcia \\
\hline Nav. & Navarra \\
\hline Sal. & Salamanca \\
\hline Sant. & Santander \\
\hline
\end{tabular}




\begin{tabular}{||l|l|}
\hline \hline Seg. & Segovia \\
\hline Sev. & Sevilla \\
\hline Sor. & Soria \\
\hline Tol. & Toledo \\
\hline Val. ${ }^{*}$ & Valencia \\
\hline Vall. o Vallad. ${ }^{*}$ & Valladolid \\
\hline Viz. o Vizc. & Vizcaya \\
\hline Zam. & Zamora \\
\hline Zar. & Zaragoza \\
\hline
\end{tabular}

Los estudios realizados sobre el léxico dialectal en el diccionario demuestran que la importancia de esta edición va más allá de las abreviaturas. Por ejemplo, respecto al aragonés, Aliaga (2000: 155 y ss.) señala que el número de voces prácticamente se duplica, ya que de las 540 entradas aragonesas de 1914 se pasa a las 1.016 en 1925. Se añaden 497 artículos (de los que 25 poseen dos acepciones) y solo se suprimen 21 entradas. Igualmente, Muriano (1997-1998: 140) anota 606 acepciones con marca de Salamanca introducidas en esta edición, ${ }^{21}$ y Le Men (2001: 628) destaca las 123 voces leonesas que se incluyen como novedad. ${ }^{22}$ La importancia de esta $15^{\mathrm{a}} \mathrm{ed}$. también ha sido constatada por Aliaga (1999: 341) para el murciano, por Corrales (1992: 207) para el canario y por Campos Souto y Pérez Pascual (2006) para los galleguismos. ${ }^{23}$

La muestra con la que nosotros hemos trabajado confirma estos datos, con numerosas acepciones con marcas de diferentes provincias españolas, entre las que destacan, en efecto, Aragón y Salamanca. ${ }^{24} \mathrm{Y}$ aun cuando la Academia, en las Reglas

21 En este estudio se comprueba la influencia del vocabulario de J. Lamano en la incorporación de estas voces.

22 El dato es muy relevante, si se tiene en cuenta que en todo el siglo xx se incorporan 208 voces al diccionario de las 223 que aparecen en la $21^{\mathrm{a}}$ ed. (DRAE-1992). En la $22^{\mathrm{a}}$ ed. (DRAE-2001) el número de acepciones se reduce a 211 en 197 entradas.

23 En la comunicación «Los galleguismos en el DRAE-1884», presentada en este mismo Congreso, los autores comprueban que el despegue en el número de voces gallegas en el diccionario se produce en la $15^{\mathrm{a}}$ ed. Para el andaluz, Ahumada (2000: 54) hace más hincapié en el Diccionario manual (1927) que en la $15^{\mathrm{a}}$ edición, aunque comenta los cambios que en este aspecto introdujo la edición. Para la situación en la $21^{\text {a }}$ ed. (DRAE-2001), contamos con los estudios de Ortega (2004) para los canarismos y de Campos Souto y Pérez Pascual (2004) para los galleguismos.

24 En la letra $\mathrm{F}$ aparecen 77 nuevas marcas regionales de las hablas peninsulares en un conjunto de 57 acepciones. Un 25,34 \% de las nuevas incorporaciones incluyen, por tanto, acepciones marcadas como provincialismos. Por zonas geográficas se reparten así: Aragón (24), Salamanca (14), Extremadura, Andalucía, León y Rioja (5), Álava (4) Navarra y Asturias (3), Santander, Zamora y Albacete (2)-Albac. en abreviaturas y Alb. en el cuerpo-, y Murcia, Huesca y Logroño (1). 
de 1872 (p. 1) recomienda que «Aquellas voces de orígen provincial, cuyo uso ha llegado á generalizarse en España, perderán la nota de provincialismos [...]», en un intento por aligerar el número de notas dialectales, lo cierto es que en la edición objeto de estudio se hallan no pocos casos de acepciones ya presentes en ediciones anteriores que se marcan dialectalmente en este momento. Véanse algunos ejemplos:

\begin{tabular}{||l|l||}
\hline \multicolumn{1}{|c|}{1914} & \multicolumn{1}{|c|}{1925} \\
\hline $\begin{array}{l}\text { Faceria. (De facero, fronterizo) f. Comunión } \\
\text { de pastos que para sus ganados se prestan mu- } \\
\text { tuamente entre sí los pueblos convecinos. }\end{array}$ & $\begin{array}{l}\text { FACERÍA. (De facero, fronterizo) f. Nav. Te- } \\
\text { renos de pasto que hay en los linderos de dos o } \\
\text { más pueblos y se aprovecha por ellos en común. }\end{array}$ \\
$\begin{array}{l}\text { Falsa. (De falso) f. Ar. Desván. } \|{ }^{2} \text { Ar. Falsi- } \\
\text { Ila. } \|^{3} \text { Mús. Consonancia que [...]. }\end{array}$ & $\begin{array}{l}\text { FALSA. (De falso) f. Ar. y Murc. Desván. } \| \mathbf{2 .} \\
\text { Alb., Ar. y Méj. Falsilla. }\end{array}$ \\
\hline
\end{tabular}

La consecuencia de todo ello queda reflejada en el dato extraído de la muestra utilizada para este estudio: algo más de la cuarta parte de las acepciones incorporadas en la $15^{\mathrm{a}}$ edición del diccionario (DRAE-1925) tienen marca de regionalismo.

\section{AMERICANISMOS}

Como señala Alvar Ezquerra (1993c: 344), a partir del siglo XIX se hace expresa la voluntad de otorgar a los americanismos un espacio cada vez mayor en los diccionarios españoles. Así, aunque ya Nebrija, la propia Academia en el $D A$ o Terreros habían introducido algunas voces americanas, hay que esperar a Salvá, Domínguez o Chao para que esa presencia sea más significativa. Este proceso tiene eco en la $12^{\mathrm{a}}$ edición de la Academia (Garriga 2001: 272), pero sobre todo, en esta $15^{\text {a }}{ }^{25}$

Sirven como muestra, una vez más, las abreviaturas. Esta edición incorpora 14 nuevas referidas a países o regiones americanas, que junto a las introducidas en la $12^{\mathrm{a}}$ y $13^{\mathrm{a}}$ ediciones, constituyen un catálogo realmente detallado, que responde al deseo expresado por Cuervo (1874: 124) de que se especifique la comarca a la que están circunscritos los americanismos - con asterisco las 14 incorporadas en la $15^{\mathrm{a}}$ ed.--.26

25 Los americanismos presentes en el DA han sido estudiados por Werner (1983).

26 En la $12^{\mathrm{a}}$ ed. se incorporaron América, Antillas, Colombia, Chile, Cuba, Ecuador, Méjico, Perú y Venezuela. En la $13^{\mathrm{a}}$ ed. (DRAE-1899) se incorpora América Meridional sin cursiva, quizá por error o quizá por considerarla como indicación de procedencia etimológica; lo cierto es que en la $14^{\mathrm{a}}$ ed. (DRAE1914) pasa a cursiva. Como hemos comentado, en esta $14^{\mathrm{a}}$ ed. desaparece la marca «prov. de...», lo que hace que se supriman las abreviaturas de Chile, Cuba y Perú, nombres cortos que ya no necesitaban abreviarse, y por eso ausentes de la tabla de abreviaturas de la $14^{\mathrm{a}}$ ed. (DRAE-1914), lo que no significa que no aparecieran como marcas en las acepciones correspondientes. 


\begin{tabular}{|c|c|}
\hline Amér. & América \\
\hline Amér. Central* & América Central \\
\hline Amér. Merid. & América Meridional \\
\hline Ant. & Antillas \\
\hline Argent. ${ }^{*}$ & República Argentina \\
\hline Bol.* & Bolivia \\
\hline C. Rica* & Costa Rica \\
\hline Colom. o Colomb. & Colombia \\
\hline Ecuad. & Ecuador \\
\hline El Salv.* & El Salvador \\
\hline Guat. * & Guatemala \\
\hline Guay.* & Guayaquil \\
\hline Hond. * & Honduras \\
\hline Nicar. $*$ & Nicaragua \\
\hline P. Ric. * & Puerto Rico \\
\hline Par.* & Paraguay \\
\hline R. de la Plata* & Río de la Plata \\
\hline Salv.* & San Salvador \\
\hline Urug. * & Uruguay \\
\hline Filip. & Filipinas \\
\hline Méj. & Méjico \\
\hline Venez. & Venezuela \\
\hline
\end{tabular}

No es objeto de este estudio describir el dificultoso procedimiento de trabajo de la Academia para allegar estos materiales al diccionario, ${ }^{27}$ pero lo que sí que podemos constatar es el significativo aumento de voces y acepciones americanas que se observan en la muestra utilizada. Así, según los datos obtenidos, el 15\% de las acepciones incorporadas a la $15^{\mathrm{a}} \mathrm{ed}$. (DRAE-1925) están marcadas como americanismos. ${ }^{28}$

En este sentido, destaca la metodología que lleva a la adscripción de algunas acepciones al habla de diversos países:

27 Se pueden encontrar valiosas observaciones al respecto en Casares (1950: 294 y ss.). Los comentarios del propio diccionario a la (falta de) colaboración de las academias americanas, así como la situación general de los americanismos en los diccionarios del español, en Seco (1988: 92) y Alvar Ezquerra (1993c).

28 Respecto a las marcas diatópicas del español de América, entre el grupo de incorporaciones de la letra $\mathbf{F}$ aparecen 68 marcas en un conjunto de 34 acepciones -cinco de ellas comparten marcas con regionalismos peninsulares-. Un $15.2 \%$ de las nuevas voces incluyen, por tanto, acepciones marcadas como americanismos. Los datos corresponden a Méjico y Colombia (10), Argentina y Chile (9), Venezuela y Cuba (7), Ecuador (5), Puerto Rico y Costa Rica (3), Honduras (2) y Perú (1). La presencia de americanismos en el Diccionario manual (Real Academia Española: 1927) ha sido estudiada por Werner (1984). 
FAÑOSO, SA. adj. Méj., P. Rico y Venez. Gangoso.

FARREAR. intr. Argent. y Chile. Andar de farra o de parranda.

FECHADOR. m. Chile y Méj. Matasellos.

FÉFERES. m. pl. Colomb., C. Rica, Cuba, Ecuad. y Méj. Bártulos, trastos, baratijas.

FERROCARRILERO, RA. adj. Argent., Colomb. y Ecuad. Ferroviario.

FESTINAR. (Del lat. festinare). Colomb., Chile, Hond., Méj. y

Venez. tr. Apresurar, precipitar, activar.

Como señala López Morales (2002: 173), la incorporación de americanismos al Diccionario se ha producido con diferentes ritmos, sin una revisión sistemática, pero en los datos que aporta sobre venezolanismos se demuestra una vez más la relevancia de la $15^{\mathrm{a}}$ ed. ${ }^{29}$

\section{CONCLUSIÓN}

La $15^{a}$ edición del diccionario ( $D R A E$-1925) se confirma, en efecto, como una de las más importantes de la producción lexicográfica de la Academia. Además del simbólico cambio en el nombre del repertorio, hemos comprobado el importante aumento de las voces técnicas y dialectales, sin parangón en las ediciones anteriores. El dato de que el $40 \%$ de las incorporaciones que registra la edición consista en acepciones provinciales o americanas muestra el cambio de orientación del repertorio, hacia una norma más abierta, producto de la presión continuada que la lexicografía decimonónica y de las nuevas concepciones lingüísticas de Menéndez Pidal y su escuela.

Esta conclusión provisional, que coincide con los estudios parciales ya realizados sobre voces técnicas y dialectales en el diccionario, debe ahora verse completada con el análisis de otros aspectos de esta edición. Este es el cometido que ahora nos imponemos. De ese estudio integral obtendremos un conocimiento profundo de las características de la edición más halagada del diccionario académico. 


\section{REFERENCIAS BIBLIOGRÁFICAS}

ABAD, Francisco (1997): «Los diccionarios de la Academia (1713-1996)», Cuestiones de lexicología y lexicografía, Madrid, Cuadernos de la UNED, 165, pp. 93-113.

- (2001): «Para la periodización de los diccionarios y las gramáticas de la Academia», en S. Ruhstaller y J. Prado, eds., Tendencias en la investigación lexicográfica del español, Huelva, Universidad de Huelva, pp. 227-236.

Ahumada, Ignacio (2000): «Las aportaciones léxicas del vocabulario andaluz al DRAE», en Estudios de lexicografía regional del español, Jaén, UNED, pp. 51-73.

Aliaga, José Luis (1999): «La crítica pionera del diccionario académico: el manuscrito sobre las voces murcianas (1888) de E. Saavedra», Nueva Revista de Filología Hispánica, XLVII/2, pp. 329-361.

- (2000): Aspectos de lexicografía española. El léxico aragonés en las ediciones del diccionario académico, Zaragoza, Institución Fernando el Católico.

Alonso, Amado (1940): Castellano, español, idioma nacional. Historia espiritual de tres nombres, Buenos Aires, Losada.

Alvar Ezquerra, Manuel (1993a): «El Diccionario de la Academia en sus prólogos», en Lexicografia descriptiva, Barcelona, Biblograf, pp. 216-239.

- (1993b): «Los regionalismos en los diccionarios, y vocabularios regionales», en Lexicografía descriptiva, Barcelona, Biblograf, pp. 313-331.

- (1993c): «La recepción de americanismos en los diccionarios generales de la lengua», en Lexicografia descriptiva, Barcelona, Biblograf, pp. 343-351.

Alvar López, Manuel (1992): «El caminar del diccionario académico», en Euralex'90: Proceedings, Barcelona, Biblograf, pp. 3-27.

Azorín, Dolores (1996-1997): «La lexicografía española del s. XIX: del diccionario a la enciclopedia», Estudios de lingüística de la Universidad de Alicante, 11, pp. 111-122.

Azorín, Dolores y M. Isabel SANTAMARÍA (1998): «Los lenguajes de especialidad en los diccionarios del español de la primera mitad del siglo XIX», en J. Brumme, ed., La història dels llenguatges iberoromànics d'especialitat (segles XVII-XIX): solucions per al present, Barcelona, Universitat Pompeu Fabra, pp. 359-378.

BAJo, Francisca (1999): El vocabulario del vino en el diccionario académico [tesina], Tarragona, Universitat Rovira i Virgili, Departament de Filologies Romàniques.

Battaner, M. Paz (1996): «Terminología y diccionarios», en Jornada Panllatina de Terminologia, Barcelona, UPF, pp. 93-117. 
Campos Souto, Mar y José Ignacio Pérez Pascual (2004a): «El elemento gallego en el DRAE: de 1992 al 2001», en P. Battaner y J. DeCesaris, eds., De lexicografia, Barcelona, UPF, pp. 309-322.

- (2006): «Los galleguismos en el DRAE-1884», en Mar Campos Souto y José Ignacio Pérez Pascual, El diccionario de la Real Academia española: ayer y hoy, A Coruña, Universidade da Coruña, pp. 39-53.

CAsares, Julio (1941): Nuevo concepto del diccionario de la lengua y otros problemas de lexicografia y gramática, Madrid, Espasa-Calpe.

- (1950): Introducción a la lexicografia moderna, Madrid, CSIC.

Clavería Nadal, Gloria (2004): «La Real Academia Española a finales del siglo Xix: Notas sobre las voces americanas en la décimotercera edición del Diccionario de la Lengua Castellana», en Actas del v Congreso de Lingüística General, Madrid, Arco/Libros, pp. 621-633.

Colmenares del Valle, Edgar (1991): La Venezuela afásica del Diccionario Académico, Caracas, Grano de Oro.

Corrales, Cristóbal (1992): «Valoración de la selección de canarismos en el DRAE», en Estudios filológicos en homenaje a Eugenio de Bustos Tovar, Salamanca, Universidad de Salamanca, I, pp. 207-218.

Cuervo, R. José (1874 [1948]): «Observaciones sobre el Diccionario de la Real Academia Española (Undécima edición, año de 1869)», en Disquisiciones sobre filología castellana, Buenos Aires, El Ateneo, pp. 119-145.

DA-1726-1739. Real Academia Española (1726-1739): Diccionario de la lengua castellana, Madrid, Francisco del Hierro.

DMile-1927. Real Academia Española (1927): Diccionario manual e ilustrado de la lengua española, Madrid, Espasa-Calpe.

DRAE-1884. Real Academia Española (1884 ${ }^{12}$ ): Diccionario de la lengua castellana, Madrid, Gregorio Hernando.

DRAE-1899. Real Academia Española (1899 $\left.{ }^{13}\right)$ : Diccionario de la lengua castellana, Madrid, Hernando y Cía.

DRAE-1914. Real Academia Española (1914 $\left.{ }^{14}\right)$ : Diccionario de la lengua castellana, Madrid, Sucesores de Hernando.

DRAE-1925. Real Academia Española $\left(1925^{15}\right)$ : Diccionario de la lengua española, Madrid, Calpe.

DRAE-1970. Real Academia Española (1970 $\left.{ }^{19}\right)$ : Diccionario de la lengua española, Madrid, EspasaCalpe.

DRAE-1992. Real Academia Española (19921): Diccionario de la lengua española, Madrid, EspasaCalpe. 
DRAE-2001. Real Academia Española (200122): Diccionario de la lengua española, Madrid, EspasaCalpe.

Gállego, Raquel (1999): El léxico de la fotografía en los diccionarios académicos [tesina], Tarragona, Universitat Rovira i Virgili, Departament de Filologies Romàniques, pp. 95101 y $157-158$.

Garriga, Cecilio (1996): «Notas al léxico económico del siglo XVIII», en A. Alonso, L. Castro, B. Gutiérrez y J. A. Pascual, eds., Actas del III Congreso Internacional de Historia de la Lengua Española, Madrid, Arco/Libros, pp. 1279-1288.

- (1996-1997): «Penetración del léxico químico en el DRAE: la edición de 1817», Revista de Lexicografia, 3, pp. 59-80.

- (2001): «Sobre el diccionario académico: la 12a ed. (1884)», en A. M. Medina Guerra, ed., Estudios de lexicografía diacrónica del español, Málaga, Universidad de Málaga, pp. 263-315.

GonZÁlez Ollé, F. (1978): «El establecimiento del castellano como lengua oficial», Boletín de la Real Academia Española, LVIII, pp. 229-280.

Gutiérrez Cuadrado, Juan (1989): «La lengua y las relaciones hispanoamericanas alrededor de 1900: ideología y trabajo lingüístico», en J. L. Peset, coord., Ciencia, vida y espacio en Iberoamérica, Madrid, CSIC, I, pp. 465-497.

— y José Antonio Pascual (1992): «A propósito de las Actas del Congreso Literario Hispanoamericano de 1892», en Actas del Congreso Literario Hispanoamericano de 1892, Madrid, Instituto Cervantes, pp. IX-XXXI.

Le Men, Janick (2001): «Las localizaciones geográficas en los diccionarios académicos (desde el Diccionario de Autoridades hasta el DRAE-92)», en M. Maquieira et al., eds., Actas del II Congreso Internacional de la Sociedad Española de Historiografía Lingüística, Madrid, Arco/Libros, pp. 623-630.

Lope Blanch, Juan M. (1983): «LLengua española o castellana? Un problema de política lingüística», en Serta Philologica F. Lázaro Carreter, Madrid, Gredos, I, pp. 309-314.

López Morales, Humberto (2002): «América en el Diccionario académico: 1992-2001», en P. Álvarez de Miranda y J. Polo, eds., Lengua y diccionarios. Estudios ofrecidos a Manuel Seco, Madrid, Arco/Libros, pp. 173-182.

MondÉJAR, José (1979): «Castellano»y «Español», dos nombres para una lengua, Granada, Universidad de Granada.

Moreno Villanueva, José Antonio (1995): El léxico de la electricidad en el Diccionario de la Academia: estudio diacrónico [tesina], Tarragona, Universitat Rovira i Virgili, Departament de Filologies Romàniques.

Muriano, Montserrat (1997-1998): «La aportación de Lamano al diccionario de la Academia», Revista de lexicografia, 4, pp. 137-148. 
Ortega, Gonzalo (2004): «El DRAE-01 y los regionalismos canarios», en P. Battaner y J. DeCesaris, eds., De lexicografia, Barcelona, UPF, pp. 661-670.

Pérez Pascual, José Ignacio (1998): Ramón Menéndez Pidal: ciencia y pasión, Valladolid, Junta de Castilla y León.

Rodríguez Ortiz, Francesc (1994): El léxico del ferrocarril en los diccionarios de la lengua española (1846-1992) [tesina], Barcelona, Universitat de Barcelona, Departamento de Filología Española.

- (1997): Introducción y desarrollo del léxico del ferrocarril en la lengua española [tesis doctoral], Barcelona, Universitat de Barcelona.

Salvador Rosa, A. (1985): «Las localizaciones geográficas en el Diccionario de Autoridades (AUT)», Lingüística española actual, vII, pp. 103-139.

Seco, Manuel (1987): «La crítica de Cuervo al Diccionario de la Academia Española», en Estudios de lexicografía española, Madrid, Paraninfo, pp. 178-193.

- (1988): «El léxico hispanoamericano en los diccionarios de la Academia Española», BRAE, LXVIII, pp. 85-98.

— (1993): «La otra voz de la Academia Española. (Notas sobre el Diccionario Manual)», en Hispanic Studies in Honor of F. W. Hodcroft, Oxford, The Dolphin Book, pp. 153-169 [también en M. Seco (2003): Estudios de lexicografia española, Madrid, Gredos, pp. 337-350].

— (1994): «Menéndez Pidal y el Diccionario Manual de la Academia», en Sin fronteras. Homenaje a María Josefa Canellada, Madrid, Ed. Complutense, pp. 539-547 [también en M. Seco (2003): Estudios de lexicografía española, Madrid, Gredos, pp. 351-361].

Werner, Reinhold (1983): «Die Amerikanismen im «Diccionario de Autoridades», en M. López de Abiada y T. Heindreich, eds., Lateinamerikanische Studien, Homenaje a Gustav Siebenmann, Madrid-Frankfurt am Main, Vervuert-Iberoamericana, pp. 1075-1082.

- (1984): «Die Amerikanismen im Handwörterbuch der Real Academia Española», en C. Segoviano y J. M. Navarro, eds., Spanien und Lateinamerika, Homenaje a Anton Bemmerlein / Inge Bemmerlein, Madrid-Frankfurt am Main, Vervuert-Iberoamericana, pp. 530-551.

Zamora Vicente, Alonso (1999): Historia de la Real Academia Española, Madrid, Espasa-Calpe. 